\title{
PERAN CERITA RAKYAT DARA MUNING DALAM PENGUKUHAN SISTEM BUDAYA
}

\section{ROLE OF DARA MUNING FOLKLORE IN THE CULTURE SYSTEM CONSTRUCTION}

\author{
Musfeptial \\ Balai Bahasa Kalimantan Barat \\ musfeptial@gmail.com
}

\begin{abstract}
ABSTRAK
Penelitian ini berjudul Peran Cerita Rakyat Dara Muning dalam Pengukuhan Sistem Budaya. Kajian ini berusaha melihat peran cerita rakyat Kalimantan Barat, khususnya Dara Muning dalam pengukuhan sistem budaya. Kerangka teori yang digunakan sebagai landasan pada kajian ini adalah pemahaman tentang teori antropologi sastra. Penelitian ini merupakan penelitian kualitatif dalam perspektif sastra. Penelitian kualitatif adalah penelitian yang bermaksud untuk memahami fenomena tentang apa yang dialami oleh subjek penelitian misalnya perilaku, persepsi, motivasi, tindakan dan lain-lain secara holistik dan dengan cara deskripsi dalam bentuk kata-kata dan bahasa pada suatu konteks khusus yang dialami dan dengan memanfaatkan berbagai metode alamiah. Sumber data pada penelitian ini adalah Kumpulan Cerita Rakyat Kalimantan Barat pada Lomba Bercerita siswa SD/MI se-Kalimatan Barat 2013 yang dihimpun oleh Unit Pelayanan Perpustakaan, Badan Perpustakaan, Kearsipan, dan Komunikasi Provinsi Kalimantan Barat dan Laporan Penelitian Proyek Pembinaan Bahasa dan Sastra Indonesia dan Daerah Kalimantan Barat tahun 2000, oleh Nyaman Sena, dkk. Hasil kajian memperlihatkan adanya peran cerita rakyat dalam pengukuhan sistem budaya yang ada. Khususnya budaya Dayak Kalimatantan Barat. Cerita rakyat Dara Muning tidak hanya berfungsi sebagai cerita rakyat saja akan tetapi juga berperan dalam pengukuhan sistem budaya yang ada pada masyarakat. Pengukuhan sistem budaya yang ada pada cerita rakyat Dara Muning setidaknya tercakup beberapa sistem budaya.
\end{abstract}

Kata kunci: cerita rakyat, pengukuhan, budaya

\begin{abstract}
This study is entitled Role of Dara Muning Folklore in the Culture System Construction. This study seeks the role of West Kalimantan folklore, especially Dara Muning in the establishment of a cultural system. The theoretical framework used as the basis for this study is an understanding of the theory of literary anthropology. Anthropological theory in the field of literature is basically a theory that focuses on the relationship between literary work and the society that creates or supports the literary work. So that literary works have a cultural dimension of benefits. This research is a qualitative research in a literary perspective. Qualitative research is research that intends to understand the phenomenon of what is experienced by the subject of research such as behavior, perceptions, motivations, actions and others holistically and by way of descriptions in the form of words and language in a specific context that is
\end{abstract}


Tuah Talino

Tahun XIII Volume 13 Nomor 2 Edisi 6 Desember 2019

ISSN 0216-079X E-ISSN 2685-3043

Balai Bahasa Kalimantan Barat

experienced and by utilizing various natural methods. Thus, a qualitative approach basically provides space for researchers to describe and interpret the meaning of existing data and facts contextually. The results of the study show the role of folklore in the strengthening of existing cultural systems. Especially the West Kalimatantan Dayak culture.

Keywords: folklore, confirmation, culture

\section{PENDAHULUAN}

Cerita rakyat, dengan istilah lainnya disebut dengan sastra lisan merupakan kekayaan khazanah budaya bangsa. Semua suku bangsa memiliki cerita rakyat. Cerita rakyat tidak hanya sekadar dongeng belaka. Bahkan, dengan menempatkan cerita rakyat sebagai dongeng belaka maka dengan sendirinya kita sudah tidak memberi ruang kepada cerita rakyat untuk dimaknai dari aspek lain. Junus (1981: 80) menjelaskan bahwa dengan menempatkan cerita rakyat sebagai cerita anakanak, maka ada dua kecenderungan yang mungkin dapat kita catat, yaitu.

1. Cerita rakyat kehilangan nilai seriusnya. Ia telah tidak lagi mengungkapkan falsafah yang mungkin pada cerita itu, ketika cerita tersebut diciptakan oleh nenek moyang kita dulunya. Yang tinggal hanyalah nilai moral.

2. Cerita rakyat mungkin hanya diartikan sesuai degan nilai moral yang dberikan padanya. Padahal, ada nilai lain yang seharusnya juga penting untuk diungkap dalam cerita rakyat.

Cerita rakyat juga berfungsi sebagi perekam ingatan kolektif suatu suku bangsa. Pada cerita rakyat akan terekam tatanan nilai, falsafah, bahkan sejarah dan budaya suatu suku bangsa. Hal ini dapat dimengerti karena masyarakat tidak memiliki pola penyimpanan atau pendokumentasi secara tulis. Dengan demikian, cerita rakyat difungsikan juga sebagai sarana perekam masyarakat.

Selain itu, cerita rakyat, juga menjadi identitas suatu suku bangsa. Amir (2013:17) menjelaskan bahwa bagi masyarakat, cerita rakyat mempunyai fungsi penting, tidak hanya sekadar sarana hiburan belaka. Lebih jauh, fungsi cerita rakyat yang diuraikan Amir tersebut dapat disimpulkan sebagai berikut.

1. Sebagai sarana pendidikan bagi budaya semua anggota masyarakat;

2. Sebagai sarana komunikasi dalam suku penutur cerita rakyat;

3. Sebagai ajang kompetensi status sosial khalayaknya; dan

4. Sebagai pengikat identitas dan solidaritas khalayaknya.

Pendapat yang hampir sama juga diuraikan Gusal (2015: 14) bahwa cerita rakyat selain berfungsi sebagai hiburan juga sebagai cara ampuh untuk mewariskan nilai-nilai.Seiring dengan itu, Levi-Strauss (dalam Endraswara 2003: 120) menjelaskan bahwa cerita rakyat (mitos) memiliki aspek sinkronis dan diakronis. Aspek sinkronis bermakna bahwa cerita rakyat diyakini sebagai peristiwa pada masa lampau namun masih relevan untuk masa kini. Sementara itu, aspek diakronis pada cerita rakyat dimaknai bahwa cerita rakyat yang berasal dari masa lampautetapi tetap ada sampaimasa sekarang.

Sebagai kekayaan bangsa, maka perlindungan, pendokumentasian, dan pengkajian terhadap cerita rakyat menjadi penting untuk dilakukan. Kepunahan suatu cerita rakyat merupakan bencana dalam bidang kebudayaan. Amir dkk. (2006: 1-2) menjelaskan bahwa punah dan hilangnya cerita rakyat sebagian suku 
Tuah Talino

Tahun XIII Volume 13 Nomor 2 Edisi 6 Desember 2019

ISSN 0216-079X E-ISSN 2685-3043

Balai Bahasa Kalimantan Barat

bangsa akan berdampak negatif pada masyarakat tersebut, antara lain mereka kehilangan kecendekiawan nenek moyangnya; mereka kehilangan estetika masa lalu, dan tidak kalah menakutkan adalah masyarakat pemilik cerita rakyat tidak akan mempunyai catatan sejarah, paling tidak rekaman budaya leluhurnya. Kesadaran akan perlindungan, pendokumentasian, dan pengkajian terhadap cerita rakyatmemunculkan setitik harapan cerah. Ismiyati (2016: 349) menjelaskan bahwa dewasa ini penyelamatan berbagai sastra tradisional (legenda,mitos, dongeng, cerita binatang, dan lain-lain) telah gencar dilakukan. Hal ini dibuktikan dengan membanjirnya buku cerita anak di toko-toko buku. Hal ini tentu patut disyukuri. Adanya kesadaran bersama dalam upaya pelestarian cerita rakyat sebagai aset budaya bangsa.

Sebagai oral tradisi, cerita rakyat dituturkan secara lisan dari mulut ke telinga. Artinya, cerita rakya sangat terikat dengan pola kelisanan. Taum (dalam Sulistyorini, 2017: 12-13) menjelaskan beberapa ciri cerita rakyat yang dapat disarikan sebagai berikut.

1. Cerita rakyat adalah teks yang dituturkan secara lisan.

2. Cerita rakyat hadir dalam berbagai bahasa daerah.

3. Cerita rakyat selalu hadir dalam versi-versi dan varian-varian yang berbeda satu sama lain. Akan tetapi, bentuk dasar cerita rakyatnya relatif tetap, terutama teks cerita rakyat yang bersifat sakral bagi masyarakat.

4. Cerita rakyat bertahan secara tradisional dan disebarkan dalam bentuk yang relatif hampir tetap dalam kurun waktu yang cukup lama.

5. Cerita rakyat mempunyai fungsi atau manfaat bagi masyarakat tradisional.

6. Cerita rakyat memiliki konvensi dan puitika sendiri yang bersifat khas dan unik.

Biasanya, nilai yang terkandung dalam certa rakyat sangat mengikat semua komunal yang ada pada suatu suku pemilik cerita rakyat tersebut. Hal ini berlaku pada hampir semua ceria rakyat yang ada. Setidaknya (Musfeptial, 2017: 267) menjelaskan bahwa kaba Malin Kundang sebagai contoh, sebagai ragam cerita rakyat Minangkabau juga mengikat masyarakat dalam pemertahanan budaya Minangkabau, yaitu sistem matrilineal.

Dalam tataran Kalimantan Barat, hal ini juga berlaku. Hadirnya cerita rakyat Dara Muning juga dapat dimaknai sebagai upaya pemertahanan dan pengukuhan sistem budaya. Banyak sistem budaya yang tercakup pada cerita ini yang selama ini luput dari pengamatan. Dengan demikian, kajian terhadapan ceritar rakyat Dara Muning menjadi menarik dan penting dilakukan. Menurut Ahimsa Putra (dalam Sidemen, 2017:13) bahwa unsur kebudayaan yang berasal dari masa lampau tidak lagi dilihat sebagai sisa-sisa budaya lama, tetapi sebagai unsur budaya yang tetap aktual dalam masyarakat, karena mempunyai fungsi tertentu.

Berdasarkan latar belakang yang telah diuraikan di atas, yang menjadi pokok masalah pada penelitian ini adalah bagaimanakah peran cerita rakyat Dara Muning dalam pengukuhan sistem budaya. Selain itu, penelitian ini bertujuan untuk memperoleh gambaran utuh mengenai peran cerita rakyat Dara Muning dalam pengukuhan sistem budaya.

Analisis ini berangkat dari pemahaman tentang teori antropologi sastra. Teori antropologi dalam bidang sastra pada dasarnya merupakan teori yang 
Tuah Talino

Tahun XIII Volume 13 Nomor 2 Edisi 6 Desember 2019

ISSN 0216-079X E-ISSN 2685-3043

Balai Bahasa Kalimantan Barat

memusatkan perhatian pada hubungan antara karya sastra dan masyarakat pencipta atau pendukung karya sastra tersebut. Ratna (2006: 252) menjelaskan bahwa dalam dunia yang imajinatif tersebut nilai-nilai antropologis berusaha dipaparkan dalam penguatan sebuah karya sastra. Cerita Rakyat yang oleh Danandjaja (1982: 50) disebut dengan cerita prosa rakyat merupakan genre folklore yang berakar dari budaya masyarakat. Dengan demikian, secara antropologis sastra karya yang muncul merpakan pengaruh dari tatanan budaya yang ada di tengah-tengah masyarakat. Kajian terhadap peran sastra dalam penguatan kebudayaan pernah dilakukan oleh Setya Yuwana Sudikan dalam Makalah yang judul Peran Sastra daerah dalam Penguatan 6 Kebudayaan Indonesia (2015). Sudikan menjelaskan bahwa sastra berperan dalam penguatan kebudayaan pada beberapa suku di Indonesia, antara lain suku Jawa, Sunda, Bali, Bugis, Banjar, dan Minang. Berbeda dengan Sudikan, kajian ini hanya membahas peran cerita Dara Muning dalam pengukuhan sistem yang ada di Kalimantan Barat.

\section{METODE PENELITIAN}

Metode yang digunakan dalam penelitian ini adalah metode deskriptif analisis. Metode deskriptif analisis dilakukan dengan cara mendeskripsikan faktafakta yang didapat dan kemudian disusul dengan analisis terhadap fakta-fakta dan data yang sudah dimiliki (Ratna, 2006:53). Metode deskriptif analisis dilakukan dengan cara mendeskripsikan data yang didapat kemudian disusul analisis terhadap fakta-fakta dan data yang sudah dimiliki (Ratna, 2006:53). Hal penting lain yang diuraikan pada kajian ini adalah menemukan makna dibalik data yang ada. Artinya, setelah memaparkan data yang ada, kajian ini memberikan interpretasi dan deskripsi analisis terhadap data cerita rakyat Dara Muning. Nazir (1983:54) menjelaskan bahwa tujuan dari penelitian deskriptif adalah untuk membuat deskripsi, gambaran, atau lukisan secara sisitematis, faktual dan akurat mengenai fakta-fakta, sifat-sifat serta hubungan antarfenomena yang diselidiki. Lebih rinci (Nazir, 1983:55) menjelaskan bahwa tugas peneliti pada kajian deskriptif adalah menerangkan hubungan, menguji hipotesis-hipotesis, membuat prediksi serta mendapatkan makna dan implikasi dari suatu masalah yang ingin dipecahkan.

Adapun yang menjadi sumber data pada penelitian ini adalah Kumpulan Cerita Rakyat Kalimantan Barat pada Lomba Bercerita siswa SD/MI seKalimatan Barat 2013 yang dihimpun oleh Unit Pelayanan Perpustakaan, Badan Perpustakaan, Kearsipan, dan Komunikasi Provinsi Kalimantan Barat dan Laporan Penelitian Proyek Pembinaan Bahasa dan Sastra Indonesia dan Daerah Kalimantan Barat tahun 2000, oleh Nyaman Sena, dkk. Diambilnya kedua sumber data ini karena karena pada bagian data pertama sudah terjadi pengeditan pada bagian akhir cerita. Sementara sumber data kedua, bagian awal cerita dianggap kurang utuh. Maka data pertama dan kedua saling melengkapi sebagai sumber data. 


\section{PEMBAHASAN}

\section{Deskripsi Cerita}

Cerita rakyat Dara Muning berkisah tentang tokoh Dara Muning dan anaknya yang bernama Bujang Munang. Bapak Bujang Munang meninggal tatkala Bujang Munang masih dalam kandungan. Sejak ditinggal oleh suaminya, Dara Muninglah yang menjadi pemimpin dalam sukunya. Selain sebagai kepala suku dan ibu rumah tangga, Dara Muning juga mempunyai akivitas lain, yaitu menganyam dan bertenun.

Pada suatu hari ketika Dara Muning dan gadis desa sibuk bertenun, tiba-tiba Bujang Munang mengganggu gadis-gadis yang sedang menenun. Melihat hal itu, Dara Muning menjadi sedikit marah. Tanpa sengaja ia memukulkan torak (batok kelapa yang diberi tangkai) ke kepala Bujang Munang.Kepalanya berdarah. Segera ia berlari meninggalkan ibunya. Kemudian Ia pergi bermain ke pinggir sungai. Sedang asyik-asyiknya bermain perahu-perahuan, ia terbawa arus sungai hingga jauh. Kemudian, dia ditemukan oleh seorang pemancing ikan dan menyerahkan Bujang Munang ke pihak kerajaan. Akhirnya, pihak kerajaan mengambil Bujang Munang dan menjadikannya sebagai anak angkat.

Setelah lama berlalu, datanglah serombongan orang ke Nanga Serawai. Pimpinan rombongan itu tidak lain adalah Bujang Munang. Karena mereka sudah lama tidak bertemu maka keduanya sudah tidak saling kenal lagi. Malah sebaliknya, timbul rasa cinta di antara mereka. Kemudian, Bujang Munang melamar Dara Muning. Akhirnya mereka melangsungkan pernikahan.

Tatkala Dara Muning dan Bujang Munang beristirahat di peraduan, Dara Muning mengelus rambut Bujang Munang. Tanpa disengaja, terlihatlah sebuah bekas luka kecil di kepala suaminya. Lalu, Dara Muning bertanya tentang luka di kepala suaminya tersebut. Bujang Munang menjelaskan bahwa luka itu akibat pukulan batok kelapa ketika ia kecil, pada saat mengganggu ibunya sedang bertenun. Alangkah kagetnya Dara Muning mendengar penjelasan suaminya tersebut. Kemudian, Dara Muning menjelaskan bahwa Bujang Munang adalah anaknya yang hilang beberapa tahun yang lalu.

Pada akhir cerita dikisahkan, mereka menyadari kesalahannya. Kemudian,mereka disarankan untuk membatalkan perkawinan dan segera mengadakan upacara menebus dosa ke dewata. Bujang Munang harus segera mendirikan poja. Poja merupakan panggung yang tinggi untuk melatakkan sesajian. Malang bagi Bujang Munang. Ketika ia membelah kayu dalamproses pembuan poja, seketika itu juga kapak yang diayunkannya melukai kemaluannya, hingga keluar darah. Melihat anaknya terluka, Dara Muning segera memberikan pertolongan. Ia menutup luka Bujang Munang dengan tangannnya supaya tidak banyak mengeluarkan darah. Tiba-tiba kilat menyambar, angin bertiup kencang, lalu turunlah hujan. Setelah hujan reda, Dara Muning dan Bujung Munang sudah berubah menjadi batu.

\section{Pengukuhan Sistem Budaya pada Cerita Rakyat Dara Muning}

Pengukuhan sistem budaya pada cerita rakya Dara Muning tidak dapat dilepaskan alur cerita yang ada pada teks cerita secara keseluruhan. Pada kajian sastra tentu teks cerita yang menjadi dasar acuan. Begitu juga dengan kajian ini, 
teks cerita tetap menjadi pupuan analisis. Adapun pengukuhan sistem budaya yang ada pada cerita rakyat dapat diuraikan sebagai berikut.

\section{Tradisi Tempat Tinggal}

Pada cerita rakyat Dara Muning dengan jelas diuraikan bagaimana pola pemukiman masyarakat. Dikisahkan bahwa pola pemukiman dan rumah tempat tinggal yang ditempati oleh Dara Muning adalah rumah adat yang didiami oleh banyak orang, seperti kutipan berikut.

Ia mendiami sebuah rumah adat yang besar di Nanga Serawai, di mana Sungai Serawai bermuara ke Sungai Melawi. Di rumah itu Dara Muning hidup bersama sejumlah dara dan dayang yang menjadi teman dan pembantunya (2013: 185).

Dari uraian di atas, tergambar bagaimana pola tempat tinggal Dara Muning. Ia hidup dan tinggal di rumah adat yang besar yang didiami oleh banyak orang. Artinya, pola tempat tinggal di rumah besar, seperti rumah panjang dengan banyak orang, seperti yang ada sekarang ini, merupakan pola pemukiman yang sudah berlagsung turun-temurun. Pola pemukiman tersebut sudah berlangsung lama. Bahkan hal itu telah terekam dengan baik di cerita rakyat Dara Muning.

Putro (2015: 66) menjelaskan bahwa hunian bagi sebagian orang tidak hanya sebagai tempat bermukim saja, tetapi dapat berfungsi luas, seperti sebagai tempat bekerja, belajar, berkumpul, bersosialisasi, dan kegiatan yang mendukung keberlangsungan hidup. Hal ini berlaku juga dengan fungsi rumah bagi masyarakat Kalimantan Barat. Juga berfungsi sebagai tempat aktivitas kehidupan sehari-hari. Artinya, fungsi rumah sebagai tempat menjalankan aktivitas kehidupan sehari-hari juga terlihat pada cerita rakyat Dara Muning. Rumah adat yang besar, tempat diam Dara Muning juga dimanfaatkan sebagai pusat pemerintahan, seperi kutipan di atas. Selain itu, akivitas bertenun dan menganyam juga dilaksanakan di rumah Dara Muning, seperti kutipan berikut.

Tak jarang ia ikut memasak,menganyam, bertenun. (2013:185)

Pola ini tentu hampir sama dengan apa yang dilakukan oleh suku Dayak Kalimantan Barat, mereka memanfaakan ruang depan rumah sebagai tempat menganyam dan bertenun.

\section{Tradisi Kepemimpinan}

Pola kepemimpina yang terekam dalam cerita rakyat Dara Muning memperlihatkan pola yang sangat fleksibel. Artinya, tidak hanya laki-laki saja yang bisa jadi pemimpin. Akan tetapi,perempuan juga bisa menjadi pemimpin. Degan demikian, persamaan gender sebenarnya telah lama berlangsung dan terekam dengan baik pada cerita rakyat DaraMuning. Tokoh rekaan Dara Muning merupakan sebagai bukti persamaam gender tersebut. Hal itu seperti kutipan berikut.

Agar hidupnya tak percuma, ia menumpahkan seluruh perhatian dan kasih sayang kepada semua rakyatnya (2017: 188).

Kutipan di atas bukti bahwa Dara Muning sebagai seorang perempuan juga memiliki etos kerja yang baik. Dara Muning menumpahkan seluruh perhatian 
Tuah Talino

Tahun XIII Volume 13 Nomor 2 Edisi 6 Desember 2019

ISSN 0216-079X E-ISSN 2685-3043

Balai Bahasa Kalimantan Barat

kepada semua rakyatnya, demi kesejahtraan rakyatnya. Artinya, Dara Muning merupakan seorang pemimpin di komunitas masyarakatnya. Dia seorang yang sangat menyayangi masyarakatnya. Selain itu, Dara Muning memiliki etos kerja yang baik. Dia sangat peduli dan memerhatikan masyarakatnya. Pada cerita ini terlihat bahwa dalam kepemimpinan, jenis kelamin tidak jadi tolok ukur. Akan tetapi, yang terpenting adalah kepedulian dan perhatian pemimpin kepada apa yang dipimpinnya. Dara Muning menjadi contoh emansipasi yang sesungguhnya, di satu sisi dia seorang pemimpin. Di sisi lain, dia tetap seorang perempuan yang terikat dengan kodrat kewanitaannya. Dia tetap menjadi ibu bagi anak semata wayangnya. Dara Muning tidak menghilangkan kodratnya sebagai ibu di rumah tangga. Hal itu terlihat seperti kutipan berikut.

Di sela-sela kesibukannya menerima kunjungan temenggung, lurah, kebaya, dan penduduk lainnya, Dara Muning masih menyempatkan diri untuk melakukan pekerjaan rumah tangga.

Tak jarang ia ikut memasak, menganyam, dan bertenun. Kecuali itu, tak lupa juga untuk merawat diri, sehingga kecantikannya sangat terpelihara (2013: 185)

Artinya, tokoh rekaan Dara Muning mampu mengatur waktu dengan baik sebagai pemimpin di masyarakat dan waktu yang harus ia berikan untuk urusan keluarganya. Selain itu, pada bagian lain dijelaskan bahwa kepemimpinan yang diemban Muning merupakan warisan dari almarhum suaminya. Ia meneruskan tahta kepemimpinan di sukunya. Hal ini terlihat seperti kutipan berikut.

Agar hidupnya tak menjadi percuma, ia menumpahkan seluruh perhatian dan kasih sayang kepada semua rakyatnya.

Ia bertekad untuk meneruskan kepemimpinan yang pernah dipercayakan kepada suaminya dengan sebaik - baiknya. Karena rakyat membutuhkannya (2013: 189).

\section{Tradisi Teknologi Tradisional.}

Masyarakat tradisional juga memiliki teknologi. Secara umum teknologi tersebut disebut dengan teknologi tradisional. Pada cerita rakyat Dara Muning teknologi tradisional yang terekam dengan baik adalah menganyam dan bertenun, seperti kutipan berikut.

Tak jarang ia memasak, menganyam, dan bertenun. Kecuali itu tak jarang juga ia merawat dirinya sehingga kecantikannya terpelihara (2013:185).

Pada bagian lain pada bagian cerita dikisahkan dan dipertegas lagi bahwa menenun menjadi pekerjaan bersama para perempuan di rumah adat, seperti kutipan berikut.

Pada suatu hari tampak Dara Muning lagi bertenun bersama-sama dengan wanita lainnya. Putranya bermain-main di dekat seorang penenun, tak jauh dari Dara Muning. Si kecil yang lincah itu kelihatan ingin pula untuk menenun (2013: 185).

Memang tidak dijelaskan alat-alat tradisional yang dipergunakan dalam menenun. Pada cerita rakyat Dara Muning hanya dijelaskan satu alat yang digunakan dalam 
menganyam, yaitu tabung bambu yang berisi benang disebut torak, seperti kutipan berikut.

Ketika wanita itu lengah. Ia merebut torak yang dipakai wanita itu bertenun. Tabung bambu yang berisi kumparan benang itu dilarikannya. Dayang tadi coba mengejarnya sambil ketawa dan menjerit gemas. Si kecil berlari ke tempat ibunya (2013: 187).

Secara umum hanya alat torak itu yang dijelaskan dalam cerita Dara Muning. Namun demikian, biasanya alat yang digunakan dalam menenun adalah kayu ulin, rotan, alat pemisah serat kapas dan bijinya, alat membentang benang, alat tenun (https://absoluteborneo.wordpress.com/tag/tenun-dayak/). Dengan demikian, setidaknya alat-alat tersebut di atas juga digunakan dalam proses menenum seperti yang dilakukan oleh Dara Muning dan para dayangnya.

Selain itu, secara implisit dalam cerita Dara Muning juga disebutkan tentang sampan bidar yang bagus dan besar. Artinya, pada masa itu masyarakat sudah memiliki teknologi tentang pembuatan sampan sebagai transportasi sungai. Hal itu terlihat secara implisit sepeti kutipan berikut,

Pada suatu hari telah datang ke Nanga Serawai sebuah bidar yang besar dan bagus. Di bidar itu tampak sejumlah 21 orang laki-laki muda.(2013: 189).

\section{Tradisi Sungai}

Bagi masyarakat pedalaman Kalimantan Barat, keberadaan sungai sangat penting. Sungai, selain sebagai sumber kehidupan, untuk memenuhi kebutuhan hidup, sungai juga berfungsi sebagai jalur transportasi. Dengan demikian,dalam konsep kemaritiman, laut dan sungai merupakan dua hal yang tidak dapat dipisahkan.

Ashary (2014:1) menjelaskan bahwa Sesungguhnya sungai pun turut menjadi bagian yang tak terpisahkan dari konsep maritim, karena sungai sangat dekat dengan keseharian masyarakat kita, baik yang tinggal di kota atau pun di desa/pedalaman. Bagaimana sungai yang menghubungkan dengan laut lepas, dan sungai yang merupakan gerbang masuk ke daratan dari pusat kerajaan yang ada di pedalaman. Maka kita akan tersadarkan bahwa sungai menjadi satu bagian penting dalam konsep maritim.

Dengan demikian, dapat dimaknai bahwa sungailah yang menjadi pintu masuk bagi transportasi laut ketika hendak ke pedalaman. Atau sebaliknya, sunga juga menjadi akses penting ketika akan menuju laut yang lebih luas. Ini dapat dipahami karena sungailah sebagai sarana transportasi pada masa lalu.

Pada cerita dara Muning, keberadaan sungai juga penting. Ini terlihat seperti pada kutipan berikut.

Pada suatu hari telah datang ke Nanga Serawai sebuah bidar yang besar dan bagus. Di bidar itu tampak sejumlah 21 orang laki-laki muda. Seoang pemuda gagah menjadi pemimpin rombongan itu datang menghadap Dara Muning setelah mendapat petunjuk dari penduduk setempat. Ia datang menghadap bersama dua orang temannya. 
Dihadapan Dara Muning pemuda itu berkata, "Nama saya Bujang Munang, kami datang dari hilir Kapuas.”(2013: 189).

Dari kutipan di atas, terlihat bagaimana pentingnya sungai bagi masyarakat Kalimantan Barat. Sungai menjadi jalur transportasi utama. Untuk mencapai bagian pedalaman Kalimantan Barat, Bujang Munang harus menggunakan bidar. Bidar merupakan perahu yang biasa digunakan untuk perang atau oleh pasukan perang satu kerajaan (KBBI V luring). Selain itu, dari kutipan cerita ini dapat diketahui bahwa sungaiyang mengaliri Pulau Kalimantan dari hulu hingga hilir adalah Sungai Kapuas.

Selain itu, pada cerita Dara Muning juga dikisahkan bahwa tradisi sungai sudah lama hidup dan berkembang di tengah masyarakat. Dari kecil masyarakat sudah hidup dan beraktivitas di sungai. Hal ini sejalan dengan apa yang telah diakukan oleh Bujang Munang pada masa kecilnya, seperti kutipan berikut.

Luka di kepalanya mulai mengering. Namun si kecil Bujang Munang masih bermain di pinggir sungai itu. Ia kemudian bermain perahu-perahuan dengan sebuah batang kelupak yang ditemukannya hanyut di sungai itu.

Batang kelupak itu bekas pohon batang yang terbakar di ladang, sangat ringan. Karenanya,memiliki daya apung yang besar. Si kecil gembira, apalagi batang kelupak itu cukup besar dan tidak oleng. Namaun, tanpa disengaja ia telah berlepas dari pinggir sungai dan hanyut terbawa arus (2013: 18).

Dalam konsep pola kemaritiman, laut dan sungai menjadi dua hal yang penting. Keduanya merupakan urat nadi kehidupan. Pada masyarakat pantai laut menjadi sumber kehidupan. Begitu juga halnya dengan sungai, bagi masyarakat agraris atau pertanian sungai menjadi sumber kehidupan pula. Hal itu dapat dilihat dari kutipan di atas. Dari kecil Bujang Munang sudah akrab dengan kehidupan di seputaran sungai. Sehingga bermain di pinggir sungai menjadi hal yang biasa bagi anak kecil seumuran Bujang Munang.

\section{Tradisi Musyawarah.}

Sebagai masyarakat homogen, pola masyarakat yang tercermin dalam cerita Dara Muning adalah pola pemukiman dengan satu pemukiman di rumah panjang. Hal ini terlihat seperti kutipan berikut.

Ia mendiami sebuah rumah adat yang besar di Nanga Serawai di mana Sungai serawai bermuara Sungai Melawai. Di rumah itu Dara Muning hidup bersama sejumlah dara dan dayang yang menjadi teman dan pembantunya (2013: 185).

Dengan pola pemukiman yang demikian, maka tradisi musyawarah sesama anggota masyarakat dalam satu komunal yang homogen ini menjadi hal yang penting.Bagi masyarakat Dayak yang berdiam di rumah panjang (betang) peran ketua adat menjadi penting. Biasanya, ketua adat dalam mengambil keputusan selalu dengan sistem musyawarah. Pola ini sudah berlangsung lama. Dalam cerita rakyat Dara Muning dijelaskan bahwa dalam sebelum mengambil putusan Dara 
Muning selalu melakukan musyawarah dengan para pembantunya dalam kepemimpinan adat. Hal itu tergambar seperti dalam kutipan berikut.

Timbul pergolakan di hatinya, antara menerima ataukah tidak. Bila diterima, masih cukupkah m udakah ia untuk menjadi istri pemuda itu? Bila ditolak, pasti ia merasa kehilangan. Pemuda itu pasti meninggalkannya.membawa rasa kecewa. Dara Muning tidak segera memberi jawaban kepada pemuda itu. Ia ingin bermusyawarah dulu dengan para temenggung (2013:191)

Dari kutipan di atas terlihat bagaimana pola musyawarah yang ada pada cerita Dara Muning. Masalah pribadi saja, Dara Muning, sebagai seorang pemimpin masih bermusyawarah dengan para pembantunya. Tentulah untuk hal-hal penting lainnya yang berhubungan dengan urusan masyarakatnya pola musyawarah terus dilaksanakan.

\section{Tradisi perkawinan (melamar dan kawin pantang)}

Secara umum di Indonesia dikenal tiga sistem kekerabatan, yaitu sistem kekerabatan parental, patrilineal, dan matrilineal. (Fitriamoko, 2017:2). Ketiga sistem kekerabatan tersebut dapat diuraikan sebagai berikut.

1. Sistem kekerabatan parental bermakna bahwa anak menghubungkan diri dengan kedua orang tuanya dan kerabat kedua orang tuanya. Artinya, pihak ayah dan ibu sama memiliki kedekatan dengan pihak anak.

2. Sistem kekerabatan patrilineal bermakna bahwa sistem kekerabatan yang mengikuti garis keturunan bapak. Pada sistem kekerabatan patrilineal pihak pengantin perempuan akan dibawa oleh pengantin laki-laki untuk menetap di rumahnya. Sistem kekrabatan sistem ini banyak dianut oleh suku bangsa yang ada di Indonesia, seperti suku Batak, Nias,Bali, dan lain-lain.

3. Sementara itu, sistem kekerabatan matrilineal dimaknai bahwa sistem kekeraban mengikuti garis keturunan ibu. Anak memiliki pertalian secara adat dengan pihak ibu dan keluarga ibu. Biasanya, setelah melakukan pernikahan pihak mempelai laki-laki akan menetap di rumah pihak mempelai perempuan. Di Indonesia sistem kakerabatan dengan pola matrilineal ini dianut oleh suku Minangkabau di Sumatera Barat.

Dalam cerita rakyat Dara Muning dikisahkan bahwa yang melamar adalah pihak laki-laki. Hal ini seperti pada kutipan berikut.

Namun, suatu ketika Dara Muning cukup terkejut dengan kenyataan bahwa

Bujang Munang telah datang untuk melamarnya (2013: 190).

Dari kutipan di atas, dapat disimpulkan bahwa pola melamar yang dilakukan pada cerita Dara Muning adalah pola patrilineal. Dimana yang melamar Dara Muning adalah Bujang Munang. Akan tetapi, pada cerita juga dikisahkan bahwa mereka berdiam di rumah panjang Dara Muning. Artinya, dalam sistem menetap mereka malah tidak mengikuti sistem patrilineal. Hal ini dapat dimaknai secara implisit seperti pada kutipan berikut.

Sementara dara yang berseru tadi tampak mengemasi peralatan tenun yang dihadapannya. Tali alat tenun yang diikatkan dipinggangnya belum dibuka. 
Bujang Munang dan Dara Muning tidak merasa terusik di peraduannya. Sebab kalaupun turun hujan sudah ada para dara dan dayang yang akan membersihkan segalanya...(2013: 192).

Dari kutipan di atas dapat dimaknai bahwa mereka tinggal di rumah panjang Dara Muning. Hal ini sesuai dengan teks cerita Dara Muning bahwa hanya di rumah Dara Muninglah ada para dara dan dayang- dayang. Selain itu, pada cerita Dara Muning juga dikisahkan bagaimana pesta perkawinan Dara Muning dan Bujang Munang. Pesta perkawinan dilaksanakan selama tujuh hari tujuh malam, yang dihadiri oleh seluruh rakyat yang berdiam di kawasan Hulu Melawi, seperti kutipan berikut.

Kemudian upacara perkawinan pun dilangsungkan dengan meriah, dihadiri rakyat yang berdatangan dari seluruh Hulu Melawi. Pesta berlangsung selama tujuh hari tujuh malam (2013: 192).

Dari kutipan di atas dapat dimaknai bahwa pesta yang dilaksanakan adalah pesta bangsawan atau pesta raja-raja. Hal ini disimbolkan dengan lamanya pesta dilaksanakan. Pesta Dara Muning dan Bujang Munang dilaksanakan selama tujuh hari tujuh malam.

Bagian lain dari alur cerita ini juga mengisahkan tentang perkawinan pantang (terlarang) yang dilakukan oleh Dara Muning dan Bujang Munang. Pada kajian pskikologi perkawinan ini disebut dengan oedipus kompleks. Pada Kamus Besar bahasa Indonesia (KBBI ofline) oedipus kompleks bermakna kelainan jiwa berupa rasa cinta yang berlebihan dan dorongan seksual yang kuat seorang lakilaki terhadap ibunya. Istilah oedipus kompleks sendiri terilhami dari cerita Romawi Kuno. Unsriana (2011: 13) menjelaskan bahwa Oedipus adalah tokoh mitologi Yunani yang tanpa diketahuinya telah membunuh ayahnya, Laius. Damono (dalam Musfeptial 2015: 306) menjelaskan bahwa dalam mitologi Yunani dijelaskan, ketika istri dari Raja Laius hamil, ahli nujum kerajaan meramalkan bahwa kelak anak yang dikandung isrinya akan membunuhnya. Kemudian setelah lahir, si anak dibuang ke hutan. Nasib baik bagi Oedipus, dia ditemukan oleh seseorang dan diserahkan ke Raja Corinthia dan dirawat dengan baik. Pada suatu ketika, setelah remaja, Oedipus berjalan-jalan ke daerah Thebes, ia bertemu dengan Raja Laius. Dalam pertemuan tersebut mereka sempat bertengkardan berkelahi yang berakibat terbunuhnya Raja Laius. Setelah berhasil membunuh raja, ia kemudian diangkat menjadi raja dan mengawini Jocasta. Kemudian, Jocasta bunuh diri setelah mengetahui yang menjadi suaminya adalah anaknya sendiri. Menarik untuk mencermati pola oedipus kompleks pada cerita Dara Muning, seperti kutipan berikut.

"Tinggallah disini beberapa lama. Rasakanlah sebagai kampung halaman sendiri," ucap Dara Muning. Sesungguhnya tawaran demikian itu sangat diharapkan oleh Bujang Munang. Setelah maksud utamanya ke daerah Nokanayan tercapai, tidak ada maksud yang lain, selain merebut hati wanita cantik itu. Sementara, Dara Muning juga berharap Bujang Munang bisa lama tingal di Nanga Serawai. Setidaknya, ada sesuatu rasa dalam hatinya.. (2013: 191). 
Pada cerita Dara Muning oedipus kompleks terjadi karena keduanya saling mencintai. Mereka sama memendam rasa cinta. Kemudian Bujang Munang dengan beraninya melamar Dara Muning. Gayung pun bersambut, Dara Muning menerima lamaran Bujang Munang. Berbeda dengan kisah mitologi Yunani di atas, keduanya kemudian berubah menjadi batu karena kutukan Jubata, setelah Dara Muning memegang kemaluan Bujang Munang yang terluka karena kapak yang tajam. Hal itu seperti kutipan berikut.

Bujang Munang membuat tebusan, yaitu sebuah poja. Tetapi malang baginya, mungkin karena kurang hati-hati, atau sudah kehendak Dewata, sewaktu membelah kayu, seketika itu juga dengan tidak disengaja, kapak yang diayunkan melukai kemaluannya. Hingga kemaluannya mengeluarkan darah. Dara Muning melihat anaknya terluka segera berlari memberikan pertolongan. Ia menutup luka di kemaluan Bujang Munang dengan tangannya supaya tidak banyak mengeluarkan darah. Tiba-tiba hari menjadi gelap, petir menggelegar, angin bertiup dengan kencangnya, lalu turun hujan yang sangat deras.Setelah hujan reda, Dara Muning, Bujang Munang, beserta pojanya sudah berubah menjadi batu ( 2013: 75).

Pada cerita Dara Muning, oedipus kompleks telah menjadikan kedua tokohnya, Dara Muning dan Bujang Munang menjadi batu. Artinya, kutukan Dewata yang menghukum keduanya. Lain halnya dengan kisah Oedipus, ibu bunuh diri, itulah cara menyelesaikan perkawinan pantang tersebut.

\section{Tradisi Pemujaan pada Makluk Gaib.}

Tradisi pemujaan pada makluk gaib merupakan sebuah keniscayaan bagi masyarakat Dayak. Mereka menyebut sang gaib dengan nama jubata. Supriyadi (2008:1) menjelaskan bahwa jubata merupakan pencipta dan pemelihara segala sesuatu yang ada di alam nyata dan alam maya. Pengukuhan tradisi pemujaan pada makluk gaib pada cerita rakyat Dara Muning terlihat ketika Dara Muning dan Bujang Munang menyadari kekeliruaannya telah melakukan kesalahan dengan menikah. Walaupun mereka melakukan pernikahan karena mereka samasama tdak mengetahui bahwa mereka adalah ibu dan anak. Akan tetapi, tetap saja mereka harus melakukan upacara adat permohonan ampun dan pemujaan pada maklik gaib. Hal itu terlihat seperti kutipan berikut.

Kemudian, mereka diberi tahu supaya membayar tebusan kepada dewata, agar tidak marah. Tebusan itu berupa mendirikan poja, yaitu sebuah panggung tinggi untuk tempat letak persembahan berupa sajian bermacammacam makanan, daging binatang, dan la in-lain. Binatang-binatang disembelih dengan disertai mantra-mantra dan dipersaksikan orang-orang yang khusus diundang. (2000: 74)

Walaupun Dara Muning dan Bujang Munang melangsungkan pernikahan dalam keadaan tidak mengetahui bahwa mereka adalah ibu dan anak. Akan tetapi, tetap saja mereka telah melakukan kesalahan atau melanggar pantang adat. Mereka harus melakukan upacara pemujaan dan permohonan ampun atas kesalahan yang telah meraka lakukan. 
Pengukuhan sistem budaya pada cerita Dara Muning merupakan bentuk lain dari perekaman da pendokumentasian sistem budaya oleh masyaralat. Sebagai milik komunal masyaakat, cerita Dara Muning tidak hanya berfungsi sebagai peghibur belaka. Akan tetapi, juga berfungsi sebagai perekam sistem budaya masa lalu yang ada da berkembang di tegah-tengah masyarakat.

\section{PENUTUP}

Dari analisis di atas, dapat disimpulkan hal-hal sebagai berikut. Cerita rakyat Dara Muning tidak hanya berfungsi sebagai cerita rakyat saja akan tetapi juga berperan dalam pengukuhan sistem budaya yang ada pada masyarakat. Pengukuhan sistem budaya yang ada pada cerita rakyat Dara Muning setidaknya tercakup tujuh sistem budaya. Pertama, adanya pengukuhan sistem pola menetap atau tempat berdiam bagi masyarakat. Kedua, terekamnya dengan baik pola kepemimpinan. Ketiga, terekamnya dengan baik tentang pola teknologi tradisonal; Keempat, adanya gambaran utuh tentang tradisi sungai. Kelima, terekam dengan baik pola musyawarah. Keenam, adanya pola perkawinan, baik pola melamar dan pantang dalam perkawinan. Ketujuh, terekamnya dengan baik pola kepercayaan yang ada di tengah-tengah masyarakat.

\section{DAFTAR PUSTAKA}

Amir, Adriyeti. (2013). Sastra Lisan Indonesia. Yogyakarta: CV. Andi Offset.

---, dkk. (2006). Pemetaan Sastra Lisan Minangkabau. Padang: Andalas University Prsss.

Gusal, La Ode. (2015). "Nilai-Nilai Pendidikan dalam Cerita Rakyat Sulawesi Tenggara". Jurnal Humanika. Nomor 15, Volume 3, Desember 2015/ ISSN 979-8296.

https://absoluteborneo.wordpress.com/tag/tenun-dayak/_Diunduh tanggal 8 Juli 2019.

http://harian.analisadaily.com/opini/news/sungai-bagian-dari-maritim/.Diunduh tanggal 8 Juli 2019.

Ismiati, Siti Ajar. (2016). "Fabel Sebagai alternatif Pendidikan Karakter dalam Pembelajarn Sastra: Kajian Terhadap Cerita Rakyat Anak dalam Majalah Gatotkaca" Prosiding Seminar Hasil Penelitian Kebahasaan dan Kesastraan, Yogyakarta, 24-25 Agustus 2016.

Junus, Umar (1981). Mitos dan Komunikasi. Jakarta: Sinar Harapan.

KBBI luring.

Kumpulan Cerita Rakyat Kalimantan Barat. (2013). Kumpuan Cerita pada Acara Lomba Bercerita Siswa SD/MI se-Kalimantan Barat di Unit Pelayanan Perpustakaan. Badan Perpustakaan, Kearsipan, dan Dokumentasi Provinsi Kalimantan Barat.

Musfeptial. (2015). "Gejala Oedipus dan Elektra Kompleks pada Naskah Drama Malin Kundang Karya Wisran Hadi” Jurnal Mlangun. Volume 10, Nomor 2, ISSN 1979-049X.

---. (2017). "Peran Kaba dalam Pengukuhan Sistem Matrillineal di Minangkabau" Jurnal Batra. Volume 2, Nomor 2, ISSN 2460-6006 
Nazir, Moh. (1983). Metode Penelitilian. Jakarta: Ghalia Indonesia.

Putro, Jawas Dwijo. (2015). "Pola Pemukiman Tepian Air Studi Kasus: Desa Sepuk Laut, Punggur Besar dan Tanjung SalehKecamatan Sungai Kakap, Kabupaten Kubu Raya”. Jurnal Langkau Betang, Volume 2, Nomor1, ISSN 2355-2484.

Ratna, Nyoman Kutha. (2006). Teori, Metode, dan Teknik Penelitian Sastra. Yogyakarta: Pustaka Pelajar.

Sena, Nyoman, dkk. (2000). "Sastra Lisan Melayu Sintang". Pontianak: Laporan Penelitian proyek Pembinaan Baasa dan Sastra Indonesia dan Daerah Kalimantan Barat.

Sidemen, Ida Ayu Wirasmini. 2017. "Paradigma da;am Studi Kebudayaan". Makalah. Jurusan Sejarah, Fakultas Ilmu Budaya, Universitas Udayana Bali.

Sudikan, Setya Yuwana. (2015) 'Peran Sastra Daerah dalam Penguatan 6 Kebudayaan Indonesia" Prosiding Konfrensi Nasional Bahasa dan Sastra III. Surakarta, 30-31 Oktober 2015, ISSN: 978-602-7373-90-7

Sulistyorini, Dwi dan Eggy Fajar Andalas (2017). Sastra Lisan Kajian Teori dan Penerapannya dalam Penelitian.Malang: Madani Kelomok Intrans Publishing.

Unsriana, Linda. (2013).“Masalah Oedipus Complex dalam Novel Umibe no Kafuka Karya Haruki Murakami”. Japanese Department, Faculty of Language and Culture, Bina Nusantara University, JurnalLingua Cultura Vol.5 No.1 Mei 2011: 10-18.

Yohanessupriyadi.blogspot.com/2008/./konsep-jubata-menurutkeyakinan-dayak. Diunduh tanggal 11 Juli 2019 